\title{
Strengthening and ductilizing of magnesium alloying with heavy rare earth elements
}

\author{
Yuanding Huang, Yulin Xu, Sihang You, Weimin Gan, Karl Ulrich Karl and Norbert Hort \\ MagIC-Magnesium Innovation Centre, Helmholtz-Zentrum Geesthacht, Max-Planck-Str. 1, 21502 \\ Geesthacht, Germany
}

\begin{abstract}
Among all alloying elements the rare earth elements (RE) play a key role in improving the ductility, high temperature strength and corrosion resistance effectively for magnesium and its alloys. The present work investigated the influences of single alloying or multi heavy REs (Gd, Dy and Y) alloying on the strengthening and ductilizing of magnesium. These heavy REs have a higher solid solubility in magnesium than that the light REs such as $\mathrm{Nd}$ and $\mathrm{Ce}$. It is found that the solid solution strengthening caused by $\mathrm{Gd}$ follows the linear relationship with the exponent $n$ value of $1 / 2$ or $2 / 3$. When adding two or more heavy REs in $\mathrm{Mg}$, owing to their interactions and resultant synergetic effects, the effectiveness of strengthening and ductilizing caused by multiple RE addition is much better than that by single RE addition.
\end{abstract}

\section{Introduction}

$\mathrm{Mg}$ alloys with a low density and high specific strength is an ideal structure engineering materials for light-weighting applications. Compared with the traditional steel or aluminum materials, they have not been widely accepted by consumer. Their commercial products are mainly fabricated by die casting. In contrast to cast products, the wrought $\mathrm{Mg}$ alloys only have a small market with a proportion of less than 5\% [1]. The main obstacles to prevent the wrought products from widespread applications are their low ductility/toughness and poor corrosion [2]. Therefore, to improve the formability and corrosion resistance becomes an urgent issue to extend the applications of $\mathrm{Mg}$ alloys.

Compared with other approaches, alloying is one of the most effective and economical ways to improve the performance of magnesium alloys. The previous investigations indicate that the additions of $\mathrm{Al}, \mathrm{Mn}, \mathrm{Zn}, \mathrm{Si}$ etc. could more or less improve the performance of magnesium alloys. Especially, the element $\mathrm{Mn}$ is an important element to improve the corrosion resistance with alleviating the impurity $\mathrm{Fe}$ in $\mathrm{Mg}$. However, the additions of these elements are sometimes only effective to increase one specific property, and deteriorate the other property. In addition, the contributions to the strength caused by their additions are still limited. Recently, although the additions of alkali elements such as $\mathrm{Ca}$ and $\mathrm{Sr}$ can not only improve the high temperature strength but also increase the room temperature ductility, their additions worsen the castability. The existence of $\mathrm{Ca}$ in $\mathrm{Mg}$ would enhance the hot tearing susceptibility and cause the mold sticking. 
Despite that REs have a higher cost than the above-mentioned elements, their additions to magnesium alloys were previously confirmed to have positive influences on their overall performance, including the low and high temperature mechanical properties, and corrosion resistance. The roles of their additions can randomize the texture and then improve the formality of magnesium alloys. During melting and casting, their additions can remove the impurities such as $\mathrm{Fe}$, $\mathrm{Ni}$ etc in magnesium. and consequently increases the corrosion resistance. The present work investigated the effects of heavy REs additions on the strengthening and ductilizing of magnesium. The synergic effects caused by multialloying with REs were explored.

\section{Experimental procedures}

$\mathrm{Mg}-\mathrm{REs}$ alloys were prepared in a steel crucible under a cover gas mixture of $\mathrm{CO}_{2}$ and $\mathrm{SF}_{6}$. After stirring at $730{ }^{\circ} \mathrm{C}$ for $0.5 \mathrm{~h}$, the alloy was cast to the mould preheated at $500{ }^{\circ} \mathrm{C}$. The filled mould was held at $670{ }^{\circ} \mathrm{C}$ for $30 \mathrm{~min}$ under the protective gas to let the heavy impurities settle to the bottom and the light impurities float up to the top of the ingots. Then the permanent mold direct chill casting was used to prepare the alloys [3]. The whole steel crucible with the melt was immerged into the continuous cooling water at a speed of 20 $\mathrm{mm} / \mathrm{s}$. As soon as the liquid level of inside melt is aligned with the height of outside water, the solidification process was finished. The weight of each obtained ingot is about $2 \mathrm{Kg}$.

Microstructures were examined using optical microscope and scanning electron microscopy (SEM). The polished samples for optical observations were taken from the same locations. They were chemically etched in a solution of $8 \mathrm{~g}$ picric acid, $5 \mathrm{ml}$ acetic acid, $10 \mathrm{ml}$ distilled water and $100 \mathrm{ml}$ ethanol. The optical microstructure was characterized using a light microscope (Reichert-Jung MeF3, Germany) with a polarization system. The specimens for SEM observations were electropolished after mechanical polishing. During electropolishing, no any water-containing agents were used. After polishing, the specimens were observed using SEM immediately.

The tensile and compressive tests were performed in accordance to DIN EN 1002 at room temperature using a Zwick 050 testing machine. For the tension tests, specimens with a gauge length of $25 \mathrm{~mm}$ and a diameter of $5 \mathrm{~mm}$ with threaded heads were used. The compressive samples had a length of $16 \mathrm{~mm}$ and a diameter of $11 \mathrm{~mm}$. All tests were performed under a strain rate of $1 \times 10^{-3} \mathrm{~s}^{-1}$. At least three specimens were tested under each condition.
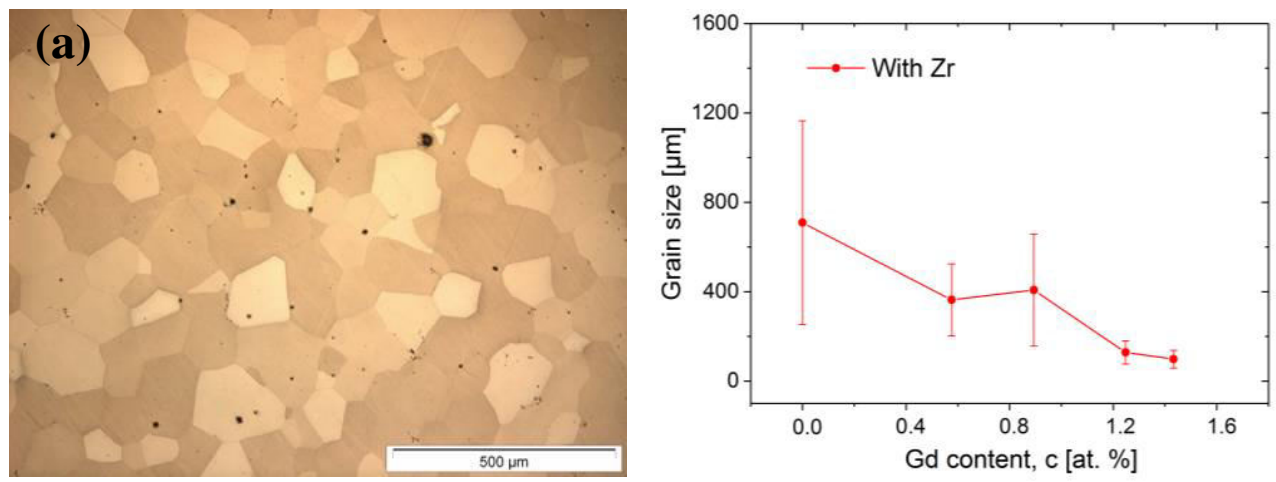

Fig. 1. (a) Optical microstructure of G15K, (b) Grain size as a function of Gd content for Mg-xGd$0.5 \mathrm{Zr}$ alloys. 


\section{Results and discussion}

\subsection{Microstructure}

Fig. 1 shows the optical microstructure of as-cast Mg-15 wt.\%Gd alloy with $\mathrm{Zr}$ and the grain size as a function of $\mathrm{Gd}$ content. With increasing the $\mathrm{Gd}$ content, the grain size decreases (Fig. 1(b)). The grain morphology is equiaxed. For these alloys without Zr, the morphology of grains changed from the columnar to the equiaxed. When the content of Gd is more than 2 wt.\%, Gd-containing intermetallics was observed. It was distributed at the dendrites and grain boundaries. When adding several heavy REs to $\mathrm{Mg}$ with a small amount no second phase were found at the dendrites and grain boundaries. The distribution of grain size is homogeneous (Fig. 2).

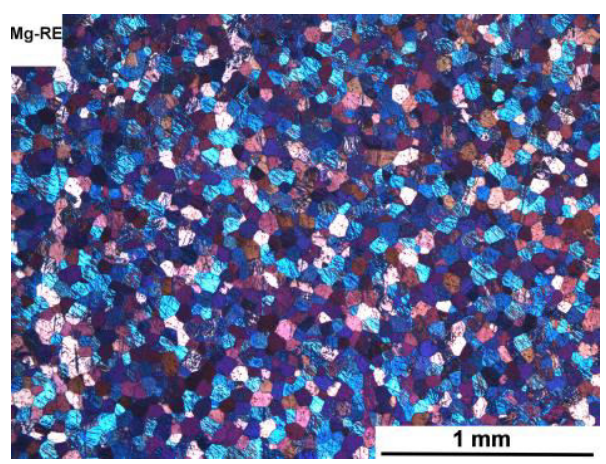

Fig. 2. Optical microstructures of Mg-0.4Y-0.4Gd-0.4Dy-0.5Zr alloy.

\subsection{Mechanical properties}

(a)
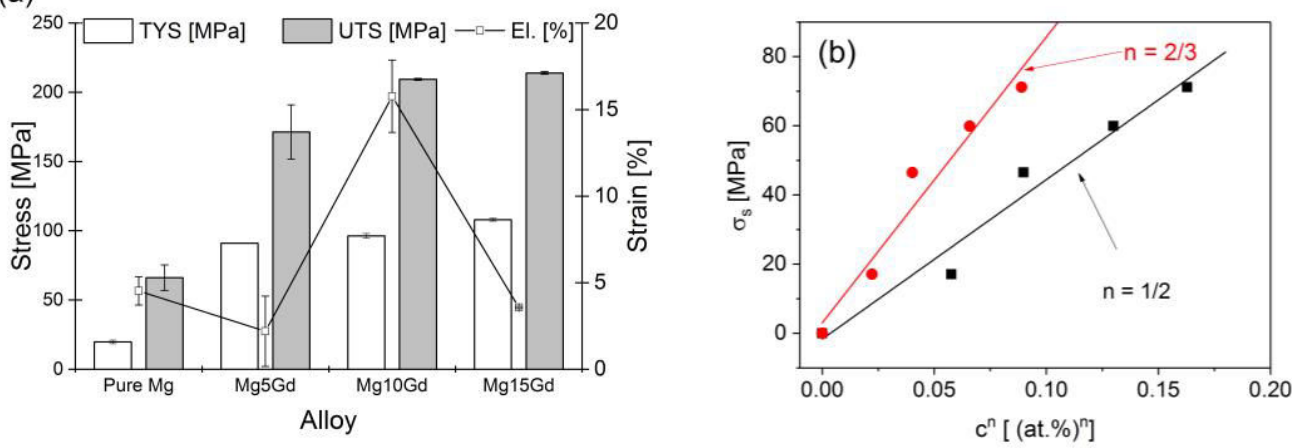

Fig. 3. (a) Tensile properties of Mg-Gd alloys with different contents of Gd, (b) Solid solution strengthening as a function of Gd content.

The tensile properties of binary Mg-Gd alloys with different Gd contents are shown in Fig. 3(a). It can be seen that the tensile yield stress (TYS) increases obviously after adding Gd element. A maximum elongation is observed for Mg10Gd binary alloy. The element Gd 
has a large atomic radius. When it is added to magnesium and its atoms substitute for $\mathrm{Mg}$ atoms to form the substitutional solid solution, a large lattice distortion near Gd atom is formed. Consequently, Gd was considered to have an apparent solid solution strengthening in magnesium. Fig. 3(b) show the solid solution strengthening caused by Gd addition after its influences on the grain size was extracted. Apparently, the solid solution strengthening caused by $\mathrm{Gd}$ follows the linear relationship. It is proportional to $\mathrm{c}^{\mathrm{n}}$, $\mathrm{c}$ is the content of $\mathrm{Gd}$ (at.\%). Fleischer and Labusch reported that the strength in metallic materials is related to the concentration of solute atoms $[4,5]$. The relationship between yield strength and solid solute concentration has the following equations with $1 / 2$ and $2 / 3$ :

\section{$\Delta \sigma \propto c^{n}$}

As shown in Fig. 3, the solid solution strengthening caused by Gd similarly follow Fleischer and Labusch's equation.

Table 1. Average mechanical properties of the alloys at room temperature.

\begin{tabular}{|l|l|l|l|l|l|l|}
\hline \multirow{2}{*}{ Alloys } & \multicolumn{3}{|l|}{ Tensile properties } & \multicolumn{3}{l|}{ Compressive properties } \\
\cline { 2 - 7 } & $\begin{array}{l}\text { TYS } \\
(\mathrm{MPa})\end{array}$ & $\begin{array}{l}\text { UTS } \\
(\mathrm{MPa})\end{array}$ & $\varepsilon(\%)$ & $\begin{array}{l}\text { TYS } \\
(\mathrm{MPa})\end{array}$ & $\begin{array}{l}\text { UTS } \\
(\mathrm{MPa})\end{array}$ & $\varepsilon(\%)$ \\
\hline AZ31 & 58 & 169 & 8.2 & 47 & 257 & 18.1 \\
\hline $\mathrm{Mg} 1.2 \mathrm{RE} 0.2 \mathrm{Zr}$ & 50 & 149 & 30.1 & 49 & 260 & 32.0 \\
\hline $\mathrm{Mg} 1.2 \mathrm{RE} 0.2 \mathrm{Zn} 0.2 \mathrm{Zr}$ & 63 & 170 & 26.9 & 62 & 280 & 28.0 \\
\hline
\end{tabular}

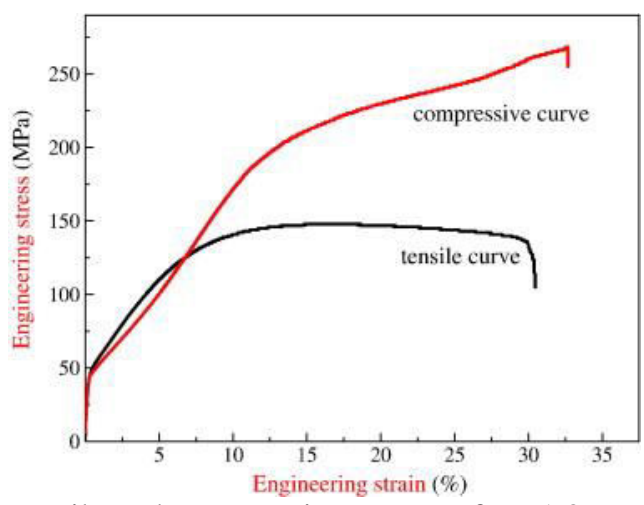

Fig. 4. Tensile and compressive curves of Mg1.2REZr alloy.

When adding two or more heavy REs in $\mathrm{Mg}$, owing to their interactions and resultant synergetic effects, the effectiveness of strengthening and ductilizing caused by multiple RE addition is expected to be much better than that by single RE addition. It is found that multiallloying with Gd, Dy and Y can improve the room temperature ductility of Mg very effectively (Table 1). The room temperature elongation for the as-cast $\mathrm{Mg}$ with multialloying can reach to more than $25 \%$. It increases by about $30 \%$ for $\mathrm{Mg}$ compared with that by single alloying. However, the increment in solid solution strengthening is limited. In addition, after multialloying with REs, the asymmetry of $\mathrm{Mg}$ between the tensile and compressive yield behaviours is largely alleviated. As shown in Fig. 4, the tensile and compressive yield stresses for the alloy Mg- $(0.4 \mathrm{Gd}, 0.4 \mathrm{Y}, 0.4 \mathrm{Dy})$ are almost the same. This indicates that after multialloying with REs the deformation homogeneity is improved. The other non-basal slips become more easy. Due to the activation of more slip systems, the deformation accommodation is improved. Recent results demonstrated that the addition of REs is the most promising method to weaken the texture and improve the deformability of 
magnesium alloys [6-9]. Agnew et al concluded that the addition of $\mathrm{Y}$ can promote the $c+a$ slip, which accommodates the $c$-axis deformation and then alleviate the deformation anisotropy [10].
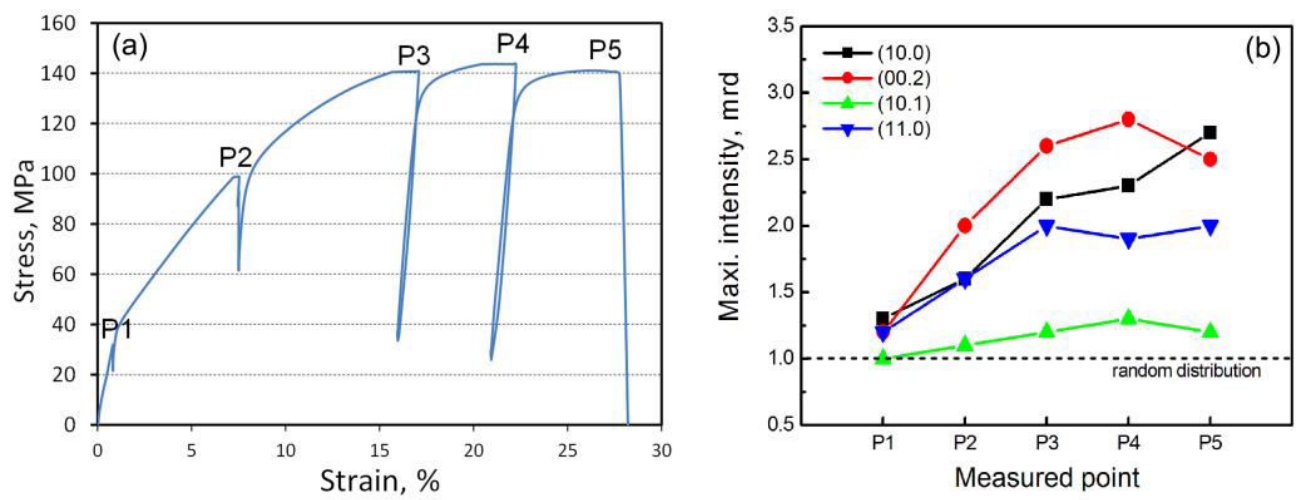

Fig. 5. (a). In situ tensile curve within the marked texture measured points; (b) maximum intensity variation of the four pole figures as indicated. Alloy: $\mathrm{Mg}-04 \mathrm{Gd}-\mathrm{Zr}$.

Fig. 5 shows the texture measured point on the tensile curve and 5(b) plots the variation of maximum intensity of the pole figures (10.0), (00.2), (10.1) and (11.0), respectively. Point $\mathrm{P} 1$ before the yield strength shows a random orientation distribution. Fast increase of the intensity in (00.2) from P2 to P3 which is at the strong hardening stage indicates a predominated basal plane sliding. This $<\mathrm{a}>$ type basal plane sliding should also be accommodated by twinning or the $<\mathrm{a}>$ type prismatic plane $\{10.0\}$ or $\{11.0\}$ since their intensities show also a sharp increase. From P3 to P5 the (00.2) and (11.0) pole figure intensities remain nearly stable, while there is still a maximum intensity increase of (10.0) planes. Hence the $<a>$ type prismatic plane sliding contributes a lot to this strain hardening platform which greatly increases the ductility of this Mg-RE alloy. Detailed descriptions together with the microstructures will be published later.

Compared with the commercial AZ31 the developed textures via in situ tensile deformation of this Mg-RE are very weaker which normally show half intensity of those of AZ31 alloy [11]. This indicates that the addition of RE could lead to a weakening of texture during deformation.

\section{Conclusion}

The additions of heavy REs in Mg can lead to the improvement of strength. The yield strength increases with the increment of RE contents. The solid solution strengthening caused by RE follows the linear relationship with the exponent $n$ value of $1 / 2$ or $2 / 3$. When adding two or more heavy REs in $\mathrm{Mg}$, owing to their interactions and resultant synergetic effects, the effectiveness of strengthening and ductilizing caused by multiple RE addition is much better than that by single RE addition. With multialloying techniques, the room temperature tensile elongation of as-cast $\mathrm{Mg} 1.2 \mathrm{REZr}$ alloy can be up to $25 \%$. Its yield asymmetry is largely alleviated. The responsible mechanism is that the addition of REs can weaken the deformation texture, and therefore the deformation homogeneity is improved. 


\section{References}

1. S. H. You, Y. D. Huang, K. U. Kainer and N. Hort. Journal of Magnesium and Alloys 5, 239-253 (2017).

2. L. L. Rokhlin. (Taylor and Francis, London and New York, 2003).

3. Q. M. Peng, Y. D. Huang, L. Zhou, N. Hort and K. U. Kainer. Biomaterials 31, 398403 (2010).

4. R. L. Fleischer. Acta Metallurgica 9, 996-1000 (1961).

5. R. Labusch. Physica Status Solidi 41, 659-\& (1970).

6. N. Stanford, D. Atwell, A. Beer, C. Davies and M. R. Barnett. Scripta Materialia 59, 772-775 (2008).

7. N. Stanford and M. Barnett. Scripta Materialia 58, 179-182 (2008).

8. J. Bohlen, M. R. Nürnberg, J. W. Senn, D. Letzig and S. R. Agnew. Acta Materialia 55, 2101-2112 (2007).

9. M. R. Barnett, A. Beer, D. Atwell, C. H. J. Davies and T. Abbott. In Magnesium Technology 2010, edited by S. R. Agnew, M. R. Neelameggham, E. A. Nyberg and W. H. Sillekens. (The Minerals, Metals \& Materials Society (TMS), Seattle, Washington, USA, pp 353-357, 2010).

10. S. R. Agnew, M. H. Yoo and C. N. Tomé. Acta Materialia 49, 4277-4289 (2001).

11. S. B. Yi, C. H. J. Davies, H. G. Brokmeier, R. E. Bolmaro, K. U. Kainer and J. Homeyer. Acta Materialia 54, 549-562 (2006). 